\title{
INFLUÊNCIA DA REDE SOCIAL NA ANSIEDADE DO ADOLESCENTE E O PAPEL DA ENFERMAGEM: REVISÃO INTEGRATIVA DA LITERATURA
}

\section{INFLUENCE OF THE SOCIAL NETWORK ON ADOLESCENT ANXIETY AND THE ROLE OF NURSING: INTEGRATIVE LITERATURE REVIEW}

\author{
Marcos Eduardo Pereira de Lima ${ }^{1} *$ Angelo Vinicius Dias Primo ${ }^{2}$
}

\begin{abstract}
RESUMO
Objetivo: Identificar o papel da enfermagem frente a ansiedade do adolescente causada pelo uso excessivo das redes sociais. Método: revisão integrativa, com busca nos bancos de dados LILACS, BIREME, SciELO, e Google Acadêmico. Resultados: Foram selecionados 09 artigos, dentro do recorte temporal de 2016 a 2020, que levaram a discussão de três categorias: Ansiedade causada pela Influência das Redes Sociais; Identificação Precoce da Ansiedade; e Ações da Enfermagem para a Ansiedade. Considerações finais: É natural o desejo de expor nas redes sociais determinadas situações próprias com o objetivo de compartilhar objetivos alcançados, socializar informações e opiniões. Entretanto, assim como este compartilhamento pode encantar, pode trazer consigo a ansiedade, de receber mais, tornando as conexões virtuais fonte de desejo e ao mesmo tempo angústia, gerando dependência, perdendo-se a capacidade de aproveitar e gerenciar o tempo. Cabe aos profissionais de saúde a identificação do problema precocemente e encaminhamento ao setor responsável para a busca de mais qualidade de vida.
\end{abstract}

Palavras-chave: Ansiedade; Adolescentes; Redes Sociais; Enfermagem.

\begin{abstract}
Objective: To identify the role of nursing in the face of adolescent anxiety caused by the excessive use of social networks. Specific objectives: Characterize the anxiety disorder caused by the influence of social networks; Assess the importance of family and nursing in the early identification of anxiety disorder in adolescents; Describe actions developed by nursing aimed at the adolescent's quality of life in the face of anxiety caused by social networks. Methodology: integrative review, searching LILACS, BIREME, SciELO, and Google Scholar databases. Results: 09 articles were selected, within the time frame from 2016 a 2020, which led to the discussion of three categories: Anxiety caused by the Influence of Social Networks; Early Identification of Anxiety; and Nursing Actions for Anxiety. Conclusion: It is natural to wish to expose specific situations on social networks with the aim of sharing achieved goals, ocializing information and opinions. However, just as this sharing can be enchanting, it can bring anxiety, of receiving more and more, making virtual connections a source of desire and at the same time anguish, generating dependency, losing the ability to enjoy and manage time. Nursing professionals are responsible for early identification of the problem and referral to the sector responsible for the search for better quality of life.
\end{abstract}

Keywords: Anxiety; Adolescents; Social Networks; Nursing

\footnotetext{
${ }^{1}$ Mestre em Ensino na Saúde, Assessor Técnico na Secretaria Municipal de Saúde do RJ e docente na Universidade Estácio de Sá. ORCID: https://orcid.org/0000-0003-2205-9452 E-mail: profmplima@ gmail.com

2 Graduando de Enfermagem da Universidade Castelo Branco. ORCID: https://orcid.org/0000-0002-1001-8947 E-mail: aprimo22@yahoo.com.br
} 


\section{INTRODUÇÃO}

A vida atual, ao longo dos anos, vem tornando a internet uma das ferramentas mais essenciais no cotidiano. Adolescentes e jovens adultos encontram acesso rico de informação, de comunicação instantânea e de entretenimento fazendo crescer exponencialmente o número de usuários nos últimos anos, que chegou a 2,5 bilhões em todo o mundo ${ }^{(1)}$.

Entretanto, além dos benefícios, o acesso a essa tecnologia pode ser prejudicial caso seja utilizado de forma constante e até mesmo viciante de maneira a desconectar o usuário da realidade em que está inserido. Este fato é chamado de Adicção por Internet (AI), considerada atualmente uma epidemia e preocupa mundialmente como problema de saúde mental. $\mathrm{O}$ uso problemático da internet, o vício em tecnologia ou dependência de celular e internet tornou-se uma constante. Identifica-se esse tipo de problema quando o indivíduo está acessando com muita frequência as redes sociais para diversos fins, por exemplo, comunicar com os amigos, realizar trabalho, interagir com familiares distantes do convívio por muitas horas seguidas $^{(2)}$.

Uma pesquisa recente mostra que os brasileiros desbloqueiam o celular, em média, 78 vezes ao dia. Entre pessoas com idades de
18 a 24 anos, esse número é ainda maior, subindo para uma média de 101 vezes ao dia. Normalmente esse processo se inicia por pequenas verificações de chamadas, e vai aumentando para notificações, entrar nas redes sociais, ver se a pessoa com a qual tentou contato visualizou, tornando inconveniente tanto para que usa como para as pessoas que o cercam, podendo se tornar um bom tempo do dia gasto somente nisso ${ }^{(3)}$.

Atualmente existem inúmeros sites e aplicativos, entre eles os profissionais, de relacionamento e entre outros, permitindo o compartilhamento de informações e interações entre pessoas. Site como Facebook®, LinkedIn $®, \quad$ Instagram $\AA \quad$ e Twitter ${ }^{\circledR}$, são imediatamente lembrados quando se fala em redes sociais. Inclusive foi criada a expressão FAKE NEWS, utilizada para descrever notícias mentirosas e disponibilizadas online, que rapidamente se espalham pelas redes, causando inúmeras polêmicas, como a falta de privacidade ${ }^{(4)}$.

Dentro deste contexto, os adolescentes iniciam a experimentação da vida adulta e da realidade, vivenciando novos ideais e confrontando com as imagens e fatos da vida cotidiana que outros disponibilizam, nem sempre verdadeiras. O não alcançar aquilo que foi idealizado os deixa ansiosos, achando difícil a adaptação a nova fase, que traz transformações biológicas, mudanças físicas, 
cognitivas, alteração nas emoções, personalidade, relação com outras pessoas e no convívio social ${ }^{(5)}$.

Neste ponto, é necessário relembrar que no Brasil, o Estatuto da Criança e do Adolescente (ECA), Lei 8.069, de 1990, passou a considerar criança a pessoa de até 12 anos de idade incompletos e define adolescência como a faixa etária de 12 a 18 anos de idade ${ }^{(6)}$.

Igualmente, destaca-se que a dependência do adolescente à internet, tem fatores desencadeadores diferentes que levam em conta problemas sociais (situação financeira, moradia), mudança de vida como divórcio dos pais, morte de alguém querido, e no espaço escolar, as relações com colegas e professores. Esses fatores são considerados de risco, e fazem com que os adolescentes se utilizem da internet como fuga ou um álibi, para tentar esquecer os problemas vivenciados $^{(5)}$.

Seu aprofundamento no meio eletrônico acaba por trazer inúmeros problemas, como mau gerenciamento do tempo, prejuízos físico-psicológicos e conflitos nas atividades diárias ou nos relacionamentos com amigos e familiares. $\mathrm{O}$ adolescente se torna suscetível a mudanças de humor e a vários transtornos mentais, pois utiliza seu tempo de estudo ou sono para ficar conectado, criando um ciclo vicioso e perigoso para sua saúde mental ${ }^{(7)}$.

Um dos principais transtornos mentais é a ansiedade, que relaciona emoções e agitação interior, muitas vezes seguida de comportamento nervoso. Ansiedade é um transtorno preocupante, pois acomete diversas faixas etárias de forma persistente, trazendo o medo de situações cotidianas. Assim, quanto mais acessível se torna a tecnologia para a população em geral, e principalmente para os adolescentes e crianças, maior o número de pessoas ansiosas e com idade mais baixa ${ }^{(7,8)}$

A ansiedade é uma doença que é caracterizada por trazer um "sentimento vago e desagradável de medo, apreensão, com tensão ou desconforto derivado de antecipação de perigo, de algo desconhecido ou estranho". Passa a ser reconhecido como patológico, quando os indivíduos exageram e seu uso passa a interferir na qualidade de vida, no conforto emocional, ou no desempenho diário do adolescente. Quando estão online, os adolescentes se distanciam ficando "off-line" para tudo que os cerca, deixando de se relacionar com outras pessoas, aumentam o ganho de peso, prejudicam o sono, diminuem o rendimento, podem se tornar mórbidos e depressivos ${ }^{(5)}$.

Observa-se, portanto, que com crianças e adolescentes, tudo que é considerado normal, rapidamente pode se 
transformar em vício, dificultando a identificação dos limites para o patológico em saúde mental. É necessário investigar os sintomas, pois apenas um sintoma não caracteriza o problema, e também pode dar indícios de inúmeras doenças. Quando identificados, têm significado no contexto sociofamiliar e no contexto evolutivo da criança e do adolescente. Este fato destaca a importância da existência precoce das estratégias de promoção, prevenção e intervenções na área da saúde mental da infância e da adolescência, tornando-se desafios enfrentados pela enfermagem ${ }^{(9)}$.

Justifica-se, a escolha da temática, devido ao aumento da frequência de jovens com transtorno de ansiedade e o uso em excesso de internet - redes sociais no mundo conectado ininterruptamente.

A dependência de internet é considerada fator de risco e os adolescentes são o grupo etário mais suscetível, pois $64 \%$ dos adolescentes acessam a internet diariamente, sendo necessário compreender quando o uso se torna excessivo para intervir $^{(5)}$. Portanto, este estudo tem como intuito contribuir para capacitação de profissionais da enfermagem que lidam diretamente com este público, bem como pais e familiares. Sendo pertinente a identificação precoce do problema para uma abordagem adequada e sucesso da terapia ${ }^{(9)}$.
Considera-se o tema relevante para o social, pois estando em sociedade o indivíduo deve manter suas relações interpessoais em nível adequado, interagindo e buscando seu crescimento pessoal. Espera-se igualmente a melhoria da qualidade da convivência em família, trazendo maior participação do adolescente, tornando-o mais consciente das necessidades de cada núcleo familiar. Para a ciência, espera-se aumentar as publicações científicas, proporcionando mais discussões sobre a temática, e fazendo com que os profissionais de enfermagem reflitam a respeito da temática, atendendo com eficiência da sociedade.

Define-se como objetivo: Identificar qual o papel da enfermagem frente a ansiedade do adolescente a partir do uso excessivo das redes sociais.

\section{MÉTODO}

Para esse estudo foi realizada uma revisão integrativa, utilizando artigos relacionados ao tema. Considerou-se as seguintes fases da revisão integrativa ${ }^{(10)}$ :

\section{- Fase 1: elaboração da pergunta}

norteadora: considerada como expressão do problema de pesquisa, determinou-se: como a enfermagem pode auxiliar na redução de ansiedade do adolescente frente ao uso excessivo das redes sociais? 
- Fase 2: busca na Literatura: Para a busca, utilizou-se as bibliotecas virtuais e bases eletrônicas de dados: Literatura LatinoAmericano e do Caribe em Ciências da Saúde (LILACS), da Biblioteca Virtual em Saúde do Centro Latino-Americano e do Caribe de informações em Ciências da Saúde
(BIREME), Eletronic Libray Online (SciELO), e Google Acadêmico. Os descritores controlados e suas combinações na língua portuguesa e língua inglesa foram definidos de acordo como Descritores em Ciências da Saúde (DeCS), disponíveis no Quadro I:

Quadro I: Definição dos Descritores. Rio de Janeiro, Rio de Janeiro, Brasil, 2020.

\begin{tabular}{|c|c|c|c|}
\hline Descritores DeCS & Sinônimos & $\begin{array}{c}\text { Descritores } \\
\text { MESH }\end{array}$ & Entry Terms \\
\hline Ansiedade & ansiedade social & Anxiety & - \\
\hline Adolescente & $\begin{array}{c}\text { Adolescente, Adolescência, } \\
\text { jovens, jovem, juventude }\end{array}$ & Adolescent & - \\
& Networking Social, & & Networking, \\
& Redes Sociais, & Social, \\
Rede social & Saúde Pública, & Social & Networking \\
& $\begin{array}{c}\text { Redes Sociais na Saúde Pública, } \\
\text { Uso das Redes Sociais, } \\
\text { Uso de Rede Social, }\end{array}$ & $\begin{array}{c}\text { Network, Social, } \\
\text { Social Network }\end{array}$ \\
& Uso de Redes Sociais. & & \\
\hline Enfermagem & - & Nursing & - \\
\hline
\end{tabular}

Fonte: Os autores

Os critérios de inclusão foram texto completo, com recorte temporal de 05 anos, portanto de 2016 a 2020, somente artigos originais, em idioma inglês e português, disponíveis nas plataformas eletrônicas; e os critérios de exclusão, duplicados e fora do viés da temática.

Apresenta-se o fluxograma conforme recomendação PRISMA ${ }^{(11)}$. 
Figura I: Fluxograma Prisma, para seleção dos estudos encontrados nas bases de dados.
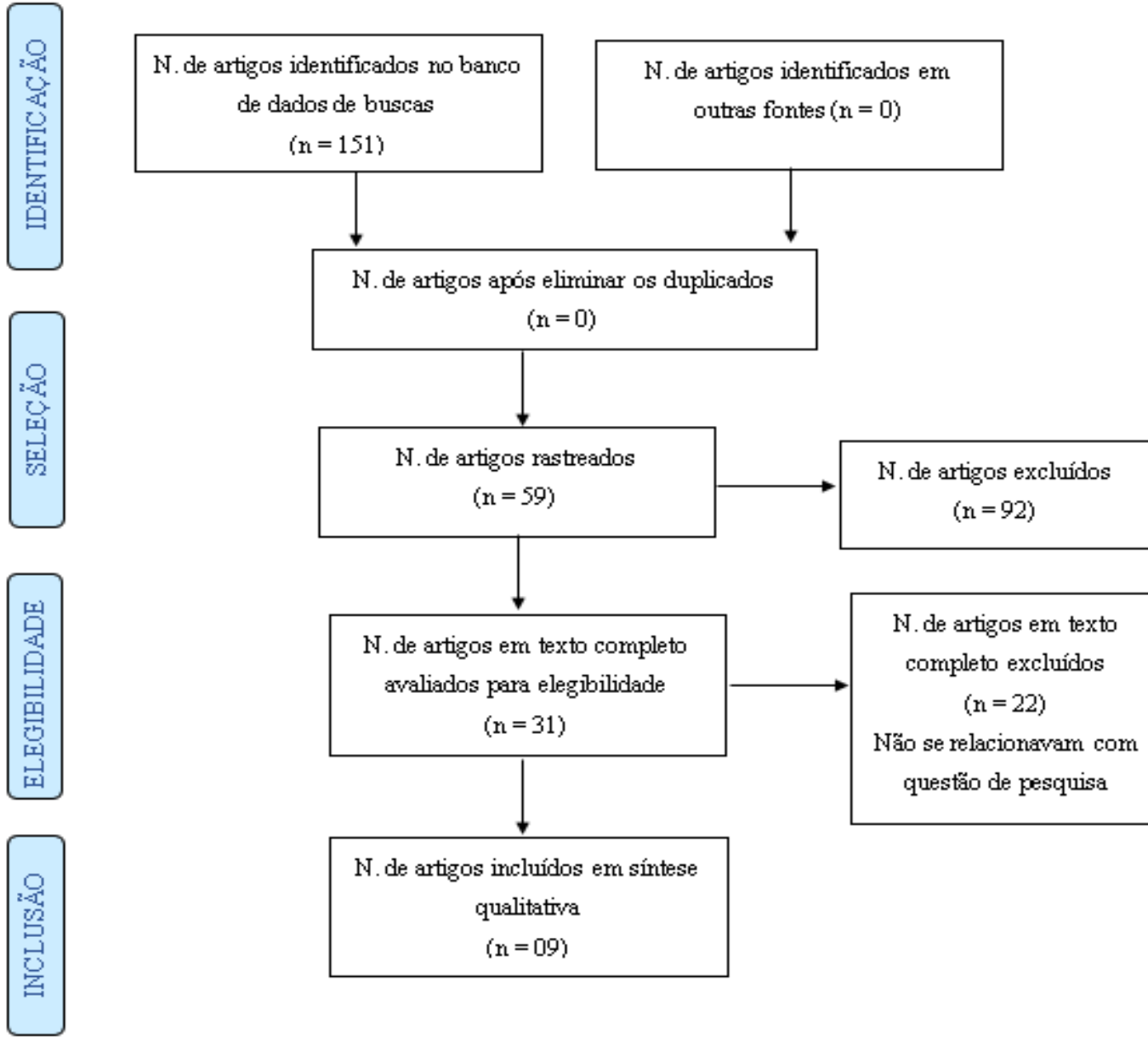

N. de artigos em texto completo avaliados para elegibilidade $(\mathrm{n}=31)$

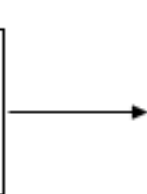

N. de artigos em texto comple to excluídos

$$
(n=22)
$$

Năo se relacionavam com questão de pesquisa

W. de artigos incluídos em síntese qualitativa $(n=09)$

Fonte: Bases de dados.

- Fase 3: Coleta de dados: Para

extrair os dados dos artigos selecionados, foi elaborado um quadro resumo, como instrumento, onde são apresentadas as principais variáveis dos 09 artigos selecionados como ano, autor, periódico, objetivos, resultados e conclusões, disponíveis nos resultados deste artigo.

- Fase 4: Sintetização: A análise dos dados das pesquisas convencionais, esta fase demanda uma abordagem organizada para ponderar o rigor e as características de cada estudo. A experiência clínica do pesquisador contribui na apuração da validade dos métodos e dos resultados.

- Fase 5: Discussão dos Resultados: Nessa fase, foi discutido os achados dos diversos atores, corroborando com outras publicações, encontrando a abordagem mais adequada para a enfermagem auxiliar na redução e prevenção da ansiedade dos adolescentes frente às redes sociais.

- Fase 6: Apresentação da revisão integrativa. 


\section{RESULTADOS}

Quadro II: Variáveis dos 09 artigos selecionados, apresentados com: ano, autor, periódico, objetivos, resultados e conclusões. Rio de Janeiro, Rio de Janeiro, Brasil, 2020.

\begin{tabular}{|c|c|c|c|c|c|}
\hline $\mathbf{N}^{\mathbf{o}}$ & Ano & Autor & Periódico & Objetivo & Resultados e Conclusões \\
\hline 01 & 2019 & $\begin{array}{l}\text { Dias, } \\
\text { Costa }\end{array}$ & $\begin{array}{l}\text { Revista } \\
\text { Adolescência } \\
\text { e Saúde }\end{array}$ & $\begin{array}{l}\text { Identificar os hábitos preferidos dos } \\
\text { adolescentes e quais temáticas na área } \\
\text { da saúde despertam interesses do } \\
\text { público. }\end{array}$ & $\begin{array}{l}\text { Adolescentes estão receptivos ao diálogo e práticas } \\
\text { educativas em torno de temáticas que envolvem o } \\
\text { respeito à diversidade e hábitos saudáveis. Acredita-se } \\
\text { que as estratégias por meio das redes sociais } \\
\text { envolvendo métodos lúdicos, com humor e diversão } \\
\text { serão mais efetivos. }\end{array}$ \\
\hline 02 & 2019 & Nobre & $\begin{array}{l}\text { Universidade } \\
\text { Federal de } \\
\text { Alagoas }\end{array}$ & $\begin{array}{l}\text { Verificar a relação entre classes de } \\
\text { habilidades sociais específicas e os } \\
\text { indicadores de ansiedade social em } \\
\text { estudantes do ensino fundamental. }\end{array}$ & $\begin{array}{l}\text { Quanto maior o grau de ansiedade social menor a } \\
\text { frequência dos comportamentos relativos à cooperação } \\
\text { e afetividade. }\end{array}$ \\
\hline 03 & 2019 & $\begin{array}{l}\text { Khoury et } \\
\text { al. }\end{array}$ & $\begin{array}{l}\text { Trends } \\
\text { Psychiatry } \\
\text { Psychother }\end{array}$ & $\begin{array}{l}\text { Melhorar a compreensão da interface } \\
\text { entre dependência de smartphone (DS) } \\
\text { e a dependência de Facebook (DF), } \\
\text { avaliamos a hipótese de que a } \\
\text { ocorrência simultânea de ambas as } \\
\text { dependências se correlaciona com o } \\
\text { número de consequências negativas } \\
\text { por elas produzidas. }\end{array}$ & $\begin{array}{l}\text { Na análise univariada, a dependência de smartphone } \\
\text { associou-se ao sexo feminino, pessoas na faixa de idade } \\
\text { entre } 18 \text { e } 25 \text { anos, rastreio para dependência de } \\
\text { Facebook, transtornos por uso de substâncias, } \\
\text { transtorno depressivo maior, transtornos de ansiedade, } \\
\text { baixos escores de estresse somado, altos escores na } \\
\text { escala de busca de sensação breve e altos escores na } \\
\text { escala de investimento corporal. O grupo rastreado } \\
\text { positivamente para DS e DF apresentou maior } \\
\text { prevalência de transtornos por uso de substâncias, } \\
\text { depressão e transtornos de ansiedade quando }\end{array}$ \\
\hline
\end{tabular}




\begin{tabular}{|c|c|c|c|c|c|}
\hline & & & & & $\begin{array}{l}\text { comparado ao grupo rastreado apenas para DS. Na } \\
\text { amostra avaliada, a comorbidade de DS e DF se } \\
\text { correlacionou a níveis mais altos de consequências } \\
\text { negativas e níveis mais baixos de satisfação com o } \\
\text { suporte social. Esses resultados sugerem que DS e DF } \\
\text { compartilham fatores de vulnerabilidade. Estudos } \\
\text { adicionais são necessários para esclarecer a direção } \\
\text { dessas associações. }\end{array}$ \\
\hline 04 & 2018 & $\begin{array}{l}\text { Fonseca et } \\
\text { al. }\end{array}$ & $\begin{array}{l}\text { Arquivos } \\
\text { Brasileiros } \\
\text { de } \\
\text { Psicologia }\end{array}$ & $\begin{array}{l}\text { Apresentar evidências de validade e } \\
\text { precisão do Cuestionario de Adicción } \\
\text { a Redes Sociales e Escala de Solidão; } \\
\text { verificar a relação da dependência das } \\
\text { redes sociais com a percepção de } \\
\text { solidão. }\end{array}$ & $\begin{array}{l}\text { Verificou-se relação positiva entre uso das redes sociais } \\
\text { e percepção de solidão e relação negativa dessa última } \\
\text { variável com autoestima. Logo, asseguram-se as } \\
\text { qualidades psicométricas dos instrumentos e verifica-se } \\
\text { que os contatos virtuais não suprem a necessidade do } \\
\text { convívio presencial. }\end{array}$ \\
\hline 05 & 2017 & $\begin{array}{l}\text { Serra, } \\
\text { Pereira }\end{array}$ & $\begin{array}{l}\text { Instituto São } \\
\text { Pedro } \\
\text { Alcantara - } \\
\text { ISPA }\end{array}$ & $\begin{array}{l}\text { Caracterizar os jovens que se dirigem } \\
\text { ao Serviço de Psiquiatria de um } \\
\text { hospital público em Lisboa e } \\
\text { descrever a frequência de } \\
\text { comportamentos autolesivos (CAL), } \\
\text { tentativas de suicídio (TS), ideação } \\
\text { suicida (IS) e vontade de morrer } \\
\text { (VM). }\end{array}$ & $\begin{array}{l}\text { Os dados revelaram que } 83,3 \% \text { dos jovens tinham } \\
\text { comportamentos autolesivos. Melhores níveis de } \\
\text { comunicação e satisfação familiar e menores níveis de } \\
\text { psicopatologia levam a menos comportamentos } \\
\text { autolesivos, tentativas de suicídio, ideação suicida e } \\
\text { vontade de morrer. As raparigas exibem maior } \\
\text { propensão do que os rapazes. Ainda, a ansiedade é a } \\
\text { variável com maior impacto nos comportamentos } \\
\text { autolesivos, tentativas de suicídio, e a depressão na } \\
\text { ideação suicida. Conclui-se também que a satisfação } \\
\text { familiar surgiu como o fator familiar com maior efeito } \\
\text { nos comportamentos autolesivos, tentativas de suicídio } \\
\text { e ideação suicida. }\end{array}$ \\
\hline
\end{tabular}




\begin{tabular}{|c|c|c|c|c|c|}
\hline 06 & 2017 & $\begin{array}{l}\text { Moromiza } \\
\text { t o et al. }\end{array}$ & $\begin{array}{l}\text { Revista } \\
\text { Brasileira de } \\
\text { Educação } \\
\text { Médica }\end{array}$ & $\begin{array}{l}\text { Investigar a correlação entre } \\
\text { indicadores do uso de internet e redes } \\
\text { sociais e a presença de sintomas } \\
\text { ansiosos e depressivos. }\end{array}$ & $\begin{array}{l}\text { O presente estudo ratifica achados prévios na literatura } \\
\text { que apontam que a adicção por internet não está } \\
\text { necessariamente relacionada com o tempo gasto na } \\
\text { internet, mas com o padrão desadaptativo do uso. Os } \\
\text { resultados aqui encontrados podem servir de base para } \\
\text { futuras intervenções em instituições de ensino que } \\
\text { busquem minimizar o prejuízo desse transtorno cada } \\
\text { vez mais presente. }\end{array}$ \\
\hline 07 & 2016 & $\begin{array}{l}\text { Méa, } \\
\text { Biffe, } \\
\text { Ferreira }\end{array}$ & $\begin{array}{l}\text { Psic. Rev. } \\
\text { São Paulo }\end{array}$ & $\begin{array}{l}\text { Investigar o padrão de uso de internet } \\
\text { e sua relação com sintomas } \\
\text { depressivos e de ansiedade em } \\
\text { adolescentes. }\end{array}$ & $\begin{array}{l}\text { Foi possível identificar que a prevalência de sintomas } \\
\text { depressivos e de ansiedade ficou dentro da faixa não- } \\
\text { clínica; contudo 61,33\% (n=92) dos adolescentes } \\
\text { apresentaram risco de dependência. A análise de } \\
\text { variância das faixas do Internet Addiction } \\
\text { Test identificou diferenças de sintomas depressivos e } \\
\text { de ansiedade; contudo, não foram identificadas } \\
\text { correlações positivas estatisticamente significativas } \\
\text { entre os escores do Internet Addiction Test e os } \\
\text { sintomas depressivos e de ansiedade. É fundamental } \\
\text { investigar o padrão de uso de internet no adolescente e } \\
\text { a presença ou não de comorbidade, para que seja } \\
\text { possível encaminhar precocemente o adolescente para } \\
\text { acompanhamento psicológico. }\end{array}$ \\
\hline 08 & 2016 & Teixeira & $\begin{array}{l}\text { Universidade } \\
\text { de Coimbra }\end{array}$ & $\begin{array}{l}\text { Estudar os padrões de uso e } \\
\text { impacto do } \\
\text { temperamento e da socialização no } \\
\text { tempo de uso diário, e ro } \\
\text { funcionamento } \\
\text { relacionamento social do adolescente }\end{array}$ & $\begin{array}{l}\text { Observou-se uma tendência estatística e significativa } \\
\text { para os sujeitos que reportam como razões do seu uso } \\
\text { das redes sociais o facto de ser mais fácil comunicar } \\
\text { por esse canal do que através da comunicação face a } \\
\text { face apresentarem níveis mais altos de ansiedade/ } \\
\text { timidez. Também se observou que os sujeitos com }\end{array}$ \\
\hline
\end{tabular}




\begin{tabular}{|c|c|c|c|c|c|}
\hline & & & & $\begin{array}{l}\text { no contexto do conjunto das suas } \\
\text { interações online e offline. }\end{array}$ & $\begin{array}{l}\text { nível mais baixo de isolamento reportam usar este meio } \\
\text { de comunicação para conversarem com os seus amigos } \\
\text { da escola. Por fim, sendo objetivo do estudo analisar o } \\
\text { impacto das redes sociais nas relações pessoais face-a- } \\
\text { face dos adolescentes, verificou-se que existe uma } \\
\text { tendência para os mesmos se encontrarem a aceder às } \\
\text { redes sociais ao mesmo tempo que estão junto dos seus } \\
\text { amigos. }\end{array}$ \\
\hline 09 & 2016 & Bento & $\begin{array}{l}\text { Instituto } \\
\text { Superior } \\
\text { Miguel } \\
\text { Torga }\end{array}$ & $\begin{array}{l}\text { Explorar a relação entre a utilização } \\
\text { do facebook, a vergonha, a depressão, } \\
\text { a ansiedade, e o stresse nos } \\
\text { adolescentes. }\end{array}$ & $\begin{array}{l}\text { Os resultados revelaram que os adolescentes que } \\
\text { utilizam o Facebook apresentam valores superiores de } \\
\text { stresse, mas não evidenciam sintomas de depressão, } \\
\text { ansiedade ou vergonha. O estudo permitiu compreender } \\
\text { melhor o impacto que o Facebook tem sobre os } \\
\text { adolescentes relativamente aos sintomas emocionais } \\
\text { negativos de depressão, ansiedade, stresse e vergonha. }\end{array}$ \\
\hline
\end{tabular}

Fonte: Dados da Pesquisa. 


\section{DISCUSSÃO}

Dos artigos selecionados dentro do recorte temporal: 2019 (3), 2018 (1), 2017(2), 2016(3). Todos estão disponíveis online, nas bibliotecas virtuais, publicados em revistas eletrônicas da saúde e no google acadêmico.

Através da análise dos artigos observou-se que todos traziam informações a respeito do uso da internet, alertando principalmente para a ansiedade causada por horas passadas em redes sociais; parte dos artigos servia também de alerta aos pais e profissionais da saúde para a identificação precoce da ansiedade, pois nem sempre os pais convivem com seus filhos horas suficientes para observar suas atividades ou monitorar seus hábitos a ponto de notar alguma alteração em seu estado emocional ou atitudes; igualmente, devido a busca envolver os profissionais da saúde e buscando responder aos objetivos propostos, observa-se que alguns dos artigos estavam voltados para ações de enfermagem que possam ajudar a diagnosticar, prevenir e tratar adolescentes que sofram de ansiedade causada pelas redes sociais.

Após essa análise, notou-se que se poderia criar categorias, agrupando por subtemáticas, para responder os objetivos propostos, sendo:

\section{Categoria 1: O Transtorno de Ansiedade} causado pela Influência das Redes Sociais

Adicção por internet, dependência, uso patológico, vício ou uso problemático são termos utilizados para designar uso exagerado da internet. Esse transtorno é descrito como preocupação intensa com o uso da internet, uso compulsivo, gasto de tempo excessivo na $w e b$, inabilidade para manejar esse tempo, considerando ainda o mundo sem internet desinteressante, irritabilidade no caso de ser interrompido quando está conectado e diminuição dos relacionamentos sociais por causa desse uso $^{(2,17)}$.

Nota-se que existem três caminhos para o uso do smartphone e, consequentemente, da internet. O primeiro é o caminho excessivo de segurança, onde os sujeitos apresentam alta ansiedade, baixa experiência de autoestima e uma necessidade de segurança que é atendida com o uso excessivo de smartphones. A segunda é a via impulsiva, correspondente ao baixo autocontrole que pode resultar no uso excessivo do smartphone, acompanhado por sintomas de dependência, um padrão antissocial de uso do smartphone e/ou comportamento arriscado no uso de telefones celulares. Terceiro, existe o caminho da extroversão, ou seja, quando os resultados viciantes são expressos em indivíduos que 
têm a necessidade constante de socializar com os outros ${ }^{(15)}$.

Observa-se que os adolescentes cada vez mais possuem aparelhos e cada vez mais estão presentes nas redes sociais, utilizando seus horários livres para navegar pelo Facebook, Instagram, entre outros. Suas outras atividades preferidas citadas, são dormir, comer e assistir televisão. Entre as redes sociais, o Facebook é hoje a plataforma mais fácil e democraticamente acessada. Tal recurso encontra-se à disposição de todos que possuem um dispositivo com acesso à internet, fato cada vez mais comum entre os estudantes brasileiros, especialmente no que se refere ao uso de celulares ${ }^{(13)}$.

Em relação às redes sociais, são interações sociais complexas promovidas por tecnologias digitais de comunicação. Elas podem influenciar a maneira como as pessoas se organizam na vida cotidiana e configuram em uma díade de elementos básicos, a saber: os atores (pessoas, instituições ou grupos) e suas interações. Esses espaços virtuais são ferramentas de socialização, interação e comunicação que interligam diversos usuários e proporciona união entre eles ${ }^{(15)}$.

Observa-se que a opção de permanecer muito tempo conectado apresenta evidentes interferências negativas na rotina do indivíduo, pois não desfrutam da presença física de outras pessoas de modo adequado, e ainda se colocam em uma condição de vulnerabilidade frente aos problemas de saúde (por exemplo, depressão, ansiedade, solidão). Tais condições podem ser observadas em grupos de crianças, adolescentes e adultos com as mais diversas características sociodemográficas, embora estudos apontem os universitários como grupo de risco ${ }^{(16)}$.

Acrescenta-se, também, a influência de fatores situacionais no desenvolvimento da dependência de internet, como problemas pessoais (situação financeira, estresse), mudanças de vida (divórcio recente, recolocação profissional, morte de alguém querido) e escolares (relação com colegas e professores). Tais situações são consideradas de risco e podem favorecer o uso da internet como fuga psicológica, desviando o usuário de acontecimentos difíceis da vida real ${ }^{(17)}$.

Neste sentido, podem surgir inúmeros transtornos mentais, principalmente a ansiedade, foco deste estudo. Este transtorno vem sendo observado cada vez mais quando relacionado ao uso compulsivo de smartphones resultando em problemas adversos. Entre esses resultados, encontramse: uma diminuição no desempenho acadêmico e no trabalho; o comprometimento dos relacionamentos interpessoais; aumento da prevalência de acidentes de trânsito; e distúrbios do sono produtividade devido ao tempo gasto no smartphone no local de trabalho ${ }^{(13) .}$ 
O Transtorno de Ansiedade é o mais comum e o terceiro mais prevalente. Os indivíduos com esse transtorno apresentam-se mais tímidos e autocríticos em situações que geram ansiedade devido à necessidade de interação social, com isso são apresentados comportamentos rígidos e com maior tensão, além de dificuldade na comunicação verbal, podendo ocasionar prejuízos no desempenho social $^{(13)}$.

A ansiedade assume expressões características na população adolescente. Diferentemente do adulto, ao invés de apresentar tristeza, os adolescentes manifestam comportamentos explosivos e irritados. Os sintomas devem prosseguir por duas semanas consecutivas, e acompanhados de sofrimento clinicamente significativo ou com prejuízos na área social, afetiva e ocupacional $^{(18) \text {. }}$

\section{A Associação Americana de} Psiquiatria distingue os sintomas de ansiedade em dois grupos: os sintomas que provém da estimulação imediata do sistema nervoso autônomo (palpitações, tremores, náuseas, sudorese, hiperventilação, parestesia, aceleração cardíaca) e aqueles surgidos pela estimulação prolongada desse sistema (fadiga, cefaleias, tonturas, dificuldades gástricas, problemas musculares). Associados a esses, estão os indicadores motores da ansiedade, manifesto por meio de sensações de inquietação e agitações psicomotoras, atitudes impacientes e reação de susto descomedidas $^{(20)}$.

Enfatiza- se que a ansiedade e o medo são responsáveis por predispor o indivíduo a situações de ameaça e perigo, abrangem fatores cognitivos, comportamentais, afetivos, fisiológicos e neurológicos que, em conjunto, alteram a percepção do indivíduo ao ambiente, originando respostas específicas e direcionando a algum tipo de ação ${ }^{(9)}$.

Deste modo, considera-se os parâmetros da existência de estado ansioso na infância, a duração da perturbação, a intensidade e as interferências com o funcionamento global da personalidade. Importa também considerar a eventual presença de mecanismos de evitamento, compulsão ou projeção (da agressividade). Deve-se ainda atentar às diferenças de sexo, visto que as meninas tendem a apresentar um temperamento ansioso (incapacidade em descontrair; receio com o futuro; ruminação do passado; mais queixas somáticas) e os rapazes, um temperamento hipertímico (oportunismo excessivo; enaltecimento; extroversão; exuberância; irritabilidade) ${ }^{(20)}$.

Quanto maiores as dificuldades que os adolescentes têm em desenvolver habilidades sociais, maior a possibilidade de desenvolver transtornos mentais. A aprendizagem das habilidades sociais importantes para o ciclo vital do desenvolvimento humano pode variar dependendo da fase em que o indivíduo se 
encontra, sendo que algumas podem apresentar mais relevância em determinadas fases do desenvolvimento, sendo: comunicação; civilidade; fazer e manter amizade; empatia, assertividade; expressão de solidariedade; manejar conflitos e resolução de problemas; expressão afeto e intimidade; coordenar grupo; e falar em público ${ }^{(14)}$.

Enquanto o tempo gasto online tornase cada vez mais excessivo, o bem-estar psicológico de alguns usuários da internet está sendo prejudicado. A presença de sintomas ansiosos pode ser gerada pelo mau uso da internet e/ou redes sociais, ou os sintomas podem estar presentes e o uso desta representa somente um mecanismo de compensação. Provavelmente, a relação entre o uso da internet e a maneira como a ansiedade é gerenciada será mais importante do que o nível da ansiedade em $\mathbf{s i}^{(17)}$.

\section{Categoria 2: Identificação Precoce do Transtorno de Ansiedade em Adolescentes pela Família}

Os jovens estão cada vez mais preocupados com o desempenho escolar e a sua admissão no ensino superior e podem sofrer pressão dos pais para que tomem decisões e até mesmo quanto a seguir o mesmo caminho como profissão. Frequentar uma escola nova, o rendimento acadêmico, a pressão dos parceiros amorosos, o fim de um relacionamento amoroso e a puberdade são acontecimentos ligados ao estresse e a ansiedade que caracterizam este período ${ }^{(22)}$.

A ansiedade pode ser experimentada no meio familiar, nas relações entre paisadolescentes e nas negociações sobre as questões de autonomia que podem desencadear facilmente conflitos. Diversos autores relatam que as famílias de adolescentes ansiosos se caracterizam por alta rigidez, baixa adaptabilidade, dificuldades na comunicação e conflitos intrafamiliares. Entretanto, a mesma base familiar pode ser a causa e o identificador de sintomas e sinais no adolescente, observando seu comportamento e suas necessidades cotidianas ${ }^{(17)}$.

Observa-se que o sentimento de bemestar e o nível de satisfação com a vida vão diminuindo se o indivíduo passar muito tempo nas redes sociais e que as interações diretas melhoram a forma como as pessoas se sentem. Em relação às outras variáveis, como a motivação pessoal para a utilização da rede social, o número de amigos, os níveis de solidão, depressão ou autoestima, não se verificou terem influência no sentimento de bem-estar dos participantes. Quanto mais sós as pessoas se sentem, mais tendem a utilizar as redes sociais ${ }^{(22)}$.

Embora o adolescente não esteja diretamente ligado ao emprego dos pais, por exemplo, as alterações e obrigações do 
mesmo terão implicações na dinâmica familiar e no seu desenvolvimento. $\mathrm{O}$ contexto é resultado dos aspectos culturais e sociais entre os quais: crenças, estilos de vida, oportunidades e padrões de mudanças sociais $^{(18)}$.

A tendência dos adolescentes ao criarem as redes sociais é procurar um local onde seria mais fácil estabelecer conversa com os outros e pode ser explicada pelo fato deste meio de comunicação dar ao sujeito a sensação de controle da relação com o outro e a sensação de estabilidade, contrariamente ao que acontece na comunicação face a face, onde este sente medo da rejeição ao se mostrar como realmente é(21).

Os sujeitos mais ansiosos nas situações e interações sociais costumam ver na internet um modo de reduzirem os seus níveis de ansiedade, e porventura, puderem evitar determinadas situações sociais. Nesse sentido, a comunicação familiar surge como uma dimensão facilitadora do funcionamento familiar, proporcionando às famílias uma modificação dos níveis da sua coesão e flexibilidade. Isto é, quando um sistema possui boas competências comunicacionais, permitindo ultrapassar crises desenvolvimentais ou acidentais, através da alteração dos níveis de coesão e flexibilidade(17).
Categoria 3: Ações de Enfermagem com o Adolescente frente a Ansiedade causada pelas Redes Sociais

Saber que os adolescentes estão com frequência ligados aos novos ambientes de relacionamento social, às novas formas de comunicação (Facebook, Instagram, WhatsApp, Twitter, entre outros tantos), não pode ser ignorado pelos profissionais de saúde e demais educadores. Melhor que ignorá-los, o ideal seria inseri-los no processo de promoção da saúde aproximando-os de conteúdo educativo ${ }^{(13)}$.

O cuidado aos adolescentes é um dos eixos prioritários da saúde pública. Pesquisas evidenciam frequentemente a alta prevalência de comportamentos de riscos à saúde entre os jovens, o que reafirma a existência de inúmeras vulnerabilidades desta população. Estas contribuem para a deflagração de diferentes agravos, potencializando fatores de riscos para o desenvolvimento de problemas de saúde nas fases de vida subsequentes ${ }^{(15)}$.

No domínio hospitalar, o enfermeiro é o profissional de saúde que interage mais com o paciente, podendo perceber no adolescente alterações somáticas que advêm de uma causa real ou imaginária e se antecipar de ocorrências que provoquem uma crise ansiosa. Após a colheita de dados, importante analisar o regime terapêutico do adolescente o incluindo. Para além, deve tomar 
conhecimento do uso regular da medicação que contribui para a diminuição do nível de ansiedade, assim como também, emerge questionar e avaliar o recurso ao uso de substâncias como tabaco, álcool, cafeína, ou outras drogas, uma vez que o consumo destas, coopera para a minimização do estado de ansiedade quando a pessoa se encontra sob efeitos dessas substâncias, mas por outro, aumenta o nível de ansiedade quando há privação das mesmas ${ }^{(22)}$.

Após a identificação do diagnóstico e a delineação de objetivos exequíveis, o enfermeiro passa as intervenções que visam dar resposta ao problema do doente, como também a concretização de alguns objetivos de enfermagem, todos em prol da melhoria da qualidade de vida do doente, descritos no timing (horário da intervenção) que o enfermeiro considerar mais pertinente. Envolve: gerir o ambiente físico, disponibilizar presença, oferecer escuta ativa, promover suporte emocional, gerir comunicação, proporcionar conforto, encorajar a se relacionar com outros, executar técnicas de relaxamento, incentivar e planejar atividades de distração ${ }^{(22)}$.

\section{CONSIDERAÇÕES FINAIS}

Ao longo desse estudo pode-se observar como a internet e as redes sociais influenciam cotidianamente a vida de milhares de pessoas, principalmente os adolescentes. Podendo seu uso indiscriminado, um potencializador para manifestações de transtornos mentais, entre eles, a ansiedade.

Portanto, há necessidade de atenção e parcimônia para o tempo de uso dessas tecnologias digitais, pois ao mesmo tempo que poderá ser um facilitador para diversas situações do cotidiano do adolescente, também pode promover inconvenientes e frustrações, as quais interferem no rendimento escolar, nas relações interpessoais reais com familiares e amigos.

A partir disso, diagnosticar precocemente estes casos é de fundamental importância, sendo de tal modo, possível intervir e direcionar o adolescente para outras atividades que promovam sua saúde mental e o resgate de hábitos saudáveis. E que se por ventura nunca existiu, que possa ser ofertado e estimulado.

É preciso reconhecer e refletir sobre essa convocação social contínua para o uso das mídias sociais na vida do adolescente, sendo necessário o alerta para a sua dependência para com as tecnologias neste mundo globalizado.

Nesse sentido, a enfermagem pode contribuir com sua capacitação técnica para acompanhar e realizar o acolhimento do adolescente que está apresentando sinais de ansiedade, podendo promover atividades de 
educação e promoção da saúde com grupos de adolescentes para o bom desempenho do tratamento e cuidado. Tendo como premissa, a integração social, incluindo a família, bem como, o respeito a subjetividade do sujeito.

\section{REFERÊNCIAS}

1. Elhai JD, Dvorak RD, Levine JC, Hall BJ. Problematic smartphone use: A conceptual overview and systematic review of relations with anxiety and depression psychopathology. J Affect Disord. 2017 Jan 1;207: 251-259. doi: 10.1016/j.jad.2016.08.030. Epub 2016 Oct 2. PMID: 27736736.

2 Silva TO, Silva LTG. Os impactos sociais, cognitivos e afetivos sobre a geração de adolescentes conectados às tecnologias digitais. 2017. [Acesso 10 Ago 2020] Revista Psicopedagogia, 34 (103), 87-97. Disponível: http://pepsic.bvsalud.org/scielo.php?script=sci_art text\&pid=S0103-

$84862017000100009 \& \operatorname{lng}=$ pt\&tlng=pt.

3. Guerra M. Como as redes sociais alimentam a nossa ansiedade. [página na internet] La Parol. 2019. [Acesso 03 Jan 2020] Disponível em: https://laparola.com.br/ansiedade-e-redes-sociais

4. Calazans JHC, Lima CAR. Sociabilidades virtuais: do nascimento da internet a popularização dos sites de redes sociais online. Encontro nacional de história da mídia, 2016. [Acesso 10 Jul 2020] Disponível em: http://www.ufrgs.br/alcar/encontros-nacionais1/9o-encontro-2013/artigos/gt-historia-da-midiadigital/sociabilidades-virtuais-do-nascimento-dainternet-a-popularizacao-dos-sites-de-redessociais-online

5. Méa CPD, Biffe EM, Ferreira VRT. Padrão de uso de internet por adolescentes e sua relação com sintomas depressivos e de ansiedade. . 2016; 25(2): 243-64.

6. Brasil. Lei n. 8069, de 13 de julho. Estatuto da Criança e do Adolescente (ECA). Fortaleza (CE):
Conselho Estadual dos Direitos da Criança e do Adolescente do Ceará; 1991.

7. Paixão RF, Patias ND, Dell'Aglio DD. Autoestima e Sintomas de Transtornos Mentais na Adolescência: Variáveis Associadas. Psicologia clínica e cultura. 2018;34; $\quad 1-8$ doi.org/10.1590/0102.3772e34436

8. Asbahr, Fernando R.Transtornos ansiosos na infância e adolescência: aspectos clínicos e neurobiológicos. Jornal de Pediatria [online]. 2004, v. 80, n. 2 suppl [Acesso 10 Jul 2021], pp. 28-34. Disponível em: <https://doi.org/10.1590/S0021-

75572004000300005>. Epub 11 Ago 2004. ISSN 1678-4782. https://doi.org/10.1590/S002175572004000300005 .

9. Clark DM; Beck AT. Terapia Cognitiva para transtornos de ansiedade. Porto Alegre: Artmed, 2012.

10. Souza MT, Silva MD, Carvalho R. Revisão integrativa: o que é e como fazer. einstein (São Paulo). 2010;8(1):102-6. https://doi.org/10.1590/s1679-45082010rw1134

11. Liberati A, Altman DG, Tetzlaff J, Mulrow C, Gøtzsche P, Ioannidis JPA, et al. The PRISMA statement for reporting systematic reviews and meta-analyses of studies that evaluate health care interventions: explanation and elaboration. PLoS Med. 2009; Jul;6(7):e1000100. doi: https://doi.org/10.1136/bmj.b2700

12. Dias IKR, Costa JV, Preferências do público adolescente: conhecer para cuidar. Revista Adolescência e Saúde, 2020; 15, supl. 1, p. 45-52

13. Nobre MR. Habilidades sociais e ansiedade social na infância e adolescência: correlações e comparações entre grupos. Dissertação apresentada ao Programa de Pós-Graduação em Psicologia - Mestrado da Universidade Federal de Alagoas, Maceió, 2019.

14. Khoury JM, Neves MDCLD, Roque MAV, Freitas AACD, da Costa MR, Garcia FD. Smartphone and Facebook addictions share common risk and prognostic factors in a sample of undergraduate students. Trends Psychiatry 
Psychother.

2019;41(4):358-68. doi.org/10.1590/2237-6089-2018-0069

15. Fonsêca PN, Couto RN, Melo CCV, Amorim LAG, Pessoa VSA. Uso de redes sociais e solidão: evidências psicométricas de escalas. Arq. bras. psicol. [Internet]. 2018 [citado 2021 Jul 09]; 70(3): 198-212. Disponível em: http://pepsic.bvsalud.org/scielo.php?script=sci_art text\&pid=S1809-52672018000300014\&lng=pt.

16. Serra RCV, Pereira MB. Funcionamento Familiar e a sua relação com Comportamentos suicidários, Depressão, Ansiedade e Stress em Adolescentes numa Amostra Clínica. Instituto Universitário Ciências Sociais e Vida, ISPA, 2017.

17. Moromizato, MS et al. O Uso de Internet e Redes Sociais e a Relação com Indícios de Ansiedade e Depressão em Estudantes de Medicina. Revista Brasileira de Educação Médica [online]. 2017, v. 41, n. 4 [Acesso 19 Jul 2020], pp. 497-504. Disponível em: $<$ https://doi.org/10.1590/198152712015v41n4RB20160118>.

18. Teixeira EIB. O uso excessivo das redes sociais pelos adolescentes. Universidade de Coimbra, Faculdade de Psicologia e de Ciências da Educação, 2016.

19. Bento MC. A utilização do Facebook por adolescentes, ansiedade, depressão, stresse e vergonha: que ligação? Coimbra, 2016.

20. American Psychiatric Association. Manual Diagnóstico e Estatístico de Transtornos Mentais, DSM-5. Porto Alegre: Artmed. 2014.

21. Fortim I, Araújo CA. Aspectos Psicológicos do uso patológico de Internet. Boletim Academia Paulista de Psicologia. 2013; 33(85), 292-311. Disponível em: http://pepsic.bvsalud.org/scielo.php?script=sci_art text\&pid=S1809-52672018000300014\&lng=pt.

22. Rebelo S., Carvalho JC, Ansiedade: Intervenções de enfermagem. Rev Presencia. 2014; [Acesso 05 Set 2020], 10(20): 1-7. Disponível em: https://www.researchgate.net/profile/Jose-Carlos-
Carvalho-

2/publication/283853274_Ansiedade_Intervencoe s_de_enfermagem/links/5657338c08ae4988a7b53 007/Ansiedade-Intervencoes-de-enfermagem.pdf

Submissão: 2021-05-09

Aprovado: 2021-07-13 